\title{
Under Suspicion: Christine Brooke-Rose, Intelligence Work, and the Theory Wars
}

Why did Christine Brooke-Rose wait until the 1990s to write about her experience fifty years prior working in the Allied code-breaking centre at Bletchley Park? Remake (1996), the text in which that experience is documented, gives a straightforward answer: 'Old-age self-indulgence? No. The old lady's publisher has asked for an autobiography. ${ }^{11}$ Writing about Remake after its publication, Brooke-Rose stated that her initial response to the request to write an autobiography was 'naturally no, never'. But 'tied up' in the 'blockage' that had followed the publication of her twelfth novel, Textermination (1991), she took up the task 'as an exercise' that 'might unblock me'. ${ }^{2}$ From its present of writing, Remake depicts a writer whose 'brain's diskettes are worn away', so many 'files won't come up in any detail'. However, one 'life-file' the text has no trouble in 'call[ing] up' relates to Brooke-Rose's experience in wartime intelligence work. ${ }^{3}$

And so, Bletchley Park provides the background for one of 'the selves' depicted in Remake: 'the baby in Geneva, the little girl in Chiswick, in Brussels, Folkestone, the young girl in Liverpool, in Thornaby-on-Tees, in Bletchley Park. ${ }^{4}$

Information on the intelligence activities (codenamed Ultra) that took place at Bletchley Park only ever circulated in the public sphere as a subject of recall; in this sense, Remake is a typical work of its kind. Detailing the 'intimations' during the war that information intercepted at Bletchley Park was poorly used - or misused - by the British state, Brooke-Rose notes that:

the intimations are confirmed in memory-wrenching detail fifty years later when the old lady, after eighteen years of silence followed by a refusal to want to remember, finally starts reading the books now allowed about Ultra over the last two decades. ${ }^{5}$

There are two timelines here, one public and one private. The public timeline is easily parsed: the three-decade period of enforced silence that Brooke-Rose describes evokes the moment in the 1970s when accounts of Ultra, first unofficial, then official, began to be published. ${ }^{6}$ The two decades that follow bring us into Remake's narrative present. But Brooke-Rose's personal timeline is less clear, creating uncertainty around the exact signification of the eighteen years, as well as the conspicuous substitution of affect ('heart-wrenching') with more functional description ('memory-wrenching').

Remake opts not to disclose the reason why silence is followed by 'a refusal to want to remember'. What is clear, however, from the way that the text circles round Bletchley Park is the fact that as an autobiography, Remake is not just preoccupied with the historicity of experience, but the historicity of acts of memory too. In Remake, the period that spans leaving Bletchley Park in the 1940s and writing about it half a century later is subdivided in different ways, characterized by particular moments and shifts, each with its own modalities and urgencies of recall.

Ultimately, this aspect of the novel points back to the present of writing, and the 'old lady' in its narrative present. Her 'refusal to want to remember' shifts to a period of reading, and then of writing. Here, it will be pertinent to reframe the terms of my initial question: what occasions this shift? To answer this question, I turn to the transnational institutional networks from which

${ }^{1}$ Christine Brooke-Rose, Remake (Manchester: Carcanet, 1996), p. 6.

${ }^{2}$ Christine Brooke-Rose, Invisible Author: Last Essays (Columbus, OH: Ohio State University Press, 2002), pp. 54-5.

${ }^{3}$ Brooke-Rose, Remake, pp. 100, 16.

${ }^{4}$ Brooke-Rose, Remake, p. 13.

${ }^{5}$ Brooke-Rose, Remake, p. 109.

${ }^{6}$ The first English-language account of Ultra was The Ultra Secret, by F. W. Winterbotham, a former RAF Group Captain and senior MI6 Officer. Published in 1973 without the approval of the British state, Winterbotham's book is mentioned in passing in Remake by Jean, a fellow Bletchley alumna, who speaks to Tess of her 'relief [...] when Freddy Winterbotham was first allowed to break the silence in '73' (Brooke-Rose, Remake, p. 132). 
much of Brooke-Rose's work emerges in one way or another. More specifically, I read Remake's recall of Bletchley Park within a textual matrix that includes Brooke-Rose's own academic writing of the 1980s-90s, as well as writing that emerged out of the so-called 'Theory Wars' of the same period. In the midst of the Theory Wars, the case of Paul de Man and the posthumous revelation of his collaborationist journalism of the 1940s gave cause for literary academics, philosophers, and cultural commentators to turn back to and reflect upon their relationship with a midcentury moment shrouded in secrecy: the ostensible parallel to Brooke-Rose's text is clear. But rather than read Remake as a direct response to the Theory Wars or the de Man affair, I trace instead a set of common concerns regarding personal history, suspicion, secrecy, disclosure, and mastery that herald a turn towards other forms of knowing. In doing so, I locate Remake at a crucial juncture in the emergence of our present post-critical moment, as well as exploring ways of reading Brooke-Rose's fiction non-schematically in relation to her own extensive body of critical work.

Throughout her career, Brooke-Rose resisted being co-opted by various schools, groups, or parties. Critical claims for her inclusion in an emergent group of 1960s experimental British novelists were weakened by her move to France in 1968. Brooke-Rose was also publicly disdainful about B. S. Johnson and Ann Quin, perhaps the two most prominent of those novelists - the former's The Unfortunates (1969) 'still a realistic and dreary novel', and the latter's Berg (1964) full of 'over-writing' and 'unbelievably long for its theme'. Another potential literary association came through the fact that Brooke-Rose often wrote novels by 'constraint' - the term she preferred to the 'lipogram' made famous by Oulipians such as Georges Perec. As Brooke-Rose later described, her first two experimental novels Out (1964) and Such (1966) both refused the 'narrative past tense, replaced by a simultaneous present tense', Between (1968) omitted the verb 'to be', and Amalgamemnon (1984) was 'written wholly in nonrealized tenses, such as the future'. ${ }^{8}$ An invitation ('by a lesser member') to join the Oulipo resulted from these formal commitments, but Brooke-Rose 'refused, for fear, perhaps, of being drawn into such attractive games'.?

As a university academic and critic, Brooke-Rose's allegiances followed a similar pattern. Though her move from London to the new experimental university at Vincennes came at the invitation of Hélène Cixous, their relationship quickly cooled, personally and professionally. Brooke-Rose's former student and literary executor Jean-Michel Rabaté depicts the differences between Brooke-Rose and Cixous: 'Christine was an enthusiastic semiotician just when Hélène Cixous was inventing the theory of écriture feminine [...] the very idea of a "feminine writing" irritated [Brooke-Rose]: she found it too essentialist'. Brooke-Rose soon moved from Cixous's smaller English department to the larger Anglo-American Studies section at Vincennes. ${ }^{10}$ Meanwhile, though many other key names in postwar French intellectual life were also based at Vincennes when Brooke-Rose was there - Gilles Deleuze, Michel Foucault, Luce Irigaray, and Jacques Lacan, for example - their membership of the departments of Philosophy or Psychoanalysis necessarily precluded automatic contacts or collaborations for Brooke-Rose. ${ }^{11} \mathrm{~A}$ further irony of Brooke-Rose's simultaneous proximity and distance to the centre of Parisian

\footnotetext{
${ }^{7}$ Christine Brooke-Rose, A Rhetoric of the Unreal: Studies in Narrative and Structure, Especially of the Fantastic (Cambridge: Cambridge University Press, 1981), p. 358; Brooke-Rose, 'Out of the Past', Spectator, 12 June 1964, p. 802.

${ }^{8}$ Brooke-Rose, Invisible Author, pp. 2, 17.

${ }^{9}$ Brooke-Rose, Invisible Author, p. 183.

${ }^{10}$ Jean-Michel Rabaté, 'Farewell to Christine Brooke-Rose', Textual Practice, 32 (2018), 193-9 (pp. 193-4).

${ }^{11}$ For further information on Brooke-Rose's move to France, see Joseph Darlington, Christine Brooke-Rose and PostWar Literature (Cham: Palgrave Macmillan, 2021), pp. 57-82.
} 
intellectual life relates to the importance of that world to university literature departments in Anglophone settings. By virtue of working in France rather than the US in the 1970s-80s, Brooke-Rose ended up being peripheral to the emergence of Theory in Anglophone critical contexts too. ${ }^{12}$

Much of Brooke-Rose's academic writing registers this marginality and shows it to be a productive catalyst for her critical approach. A comment from her 1981 critical work, $A$ Rhetoric of the Unreal, sets the tone here: 'I shall not be "nihilistic" or "deconstructive", but neither shall I impose a system, or use one theory. I shall be eclectic, plural ltd, for no reader or critic can see all aspects at the same time, and some texts respond better to some methods'. ${ }^{13}$ Collecting together Brooke-Rose's work from the second half of the 1980s, the essays in her next critical work, Stories, Theories and Things (1991), are characterized by just such an eclecticism and plurality, exhibiting a wide range of literary and philosophical reference, and a capacity to bring together this multiplicity through synthesis, synopsis, and strategic disavowal. In 'Whatever Happened to Narratology?', for example, Brooke-Rose offers an incisive critique of narratological approaches to literary criticism. In this essay, structuralism, 'however fascinating on narrative structures', is shown to have 'evolved a particularly clumsy machinery for the analysis of poetry, uneconomic, inelegant, text-destroying'. And if narratology often extended beyond its grounding in structuralism, 'in the end, it couldn't cope with narrative and its complexities, except at the price of either trivialization or of becoming a separate theoretical discourse, rarely relevant to the narrative discussed'; instead 'the study of narratological phenomena [...] turned into an endless discussion about how to speak of them'. ${ }^{14}$ Narratological and structuralist approaches were in fact Brooke-Rose's most frequent theoretical reference-point across her scholarly career - as evidenced, for example, by her frequent recourse to Algirdas Julien Greimas and Roman Jakobson in her writing, or by her more directly structuralist works, such as her $A$ Structural Analysis of Pound's Usura Canto: Jakobson's Method Extended and Applied to Free Verse (1976). Even her most experimental novel, Thru (1975), was written, she said, 'almost tongue-in-cheek for a few narratologist friends'. ${ }^{15}$ But as if to resist recuperation along these lines, 'Whatever Happened to Narratology?' seems to celebrate the eclipse of a mainstay of Brooke-Rose's own critical (and literary) work.

Given Brooke-Rose's general resistance to fixed associations, 'Whatever Happened to Narratology?' should be read not as a radical turn against her previous critical beliefs, but instead as one of many critical assertions of her intellectual freedom. At the same time, and in spite of her earlier refusal to be 'deconstructive', Stories, Theories and Things does affirm the most readily available critical alternative to structuralism that was available to literary critics of this period. The book takes poststructuralist ideas seriously, something most evident perhaps in the essay 'Id Is, Is Id?', which considers the limitations of psychoanalytic models in literary criticism. The essay begins by setting out an initial assumption that all critical statements are based in the 'copula (or concept of identity, the equation $\mathrm{A}=\mathrm{B}$ )', before showing how dependence on the copula makes much criticism prone to dogma, which is 'a scenario elaborated from one premise to be taken on trust, whether that trust be ideological or epistemological. ${ }^{16}$ Here, Brooke-Rose first levels Derrida's writing on Friedrich Nietzsche and the copula against such dogmatism, a means of introducing the 'venerable problem of whether philosophical concepts are constrained

\footnotetext{
12 Textermination, with its MLA-type conference populated by characters from world literary history, is the closest Brooke-Rose gets to indexing at length her paradoxical imbrication with and separation from literary studies in the US.

${ }^{13}$ Brooke-Rose, $A$ Rhetoric of the Unreal, p. 51.

${ }^{14}$ Christine Brooke-Rose, Stories, Theories and Things (Cambridge: Cambridge University Press, 1991), pp. $20,27$.

${ }^{15}$ Ellen J. Friedman and Miriam Fuchs, 'A Conversation with Christine Brooke-Rose', in Utterly Other Discourse: The Texts of Christine Brooke-Rose, ed. by Ellen J. Friedman and Richard Martin (Normal, IL: Dalkey Archive Press,), pp. 29-37 (p. 36)

${ }^{16}$ Brooke-Rose, Stories, Theories and Things, pp. 29, 34.
} 
by language'. ${ }^{17}$ But 'that other great deconstructor of our time', Paul de Man, proves more fruitful for Brooke-Rose. Drawing on de Man's Allegories of Reading (1979), Brooke-Rose shows how de Man uses the 'patent literariness' of Nietzsche's writing to deconstruct the 'principle of non-contradiction, ground of the identity principle'. And so in loosening the authority of the copula, de Man provides a justification, Brooke-Rose suggests, for the patently "literary" language of philosophers like Nietzsche (or Derrida, Deleuze, Serres and others), and of "human" scientists like Freud or Lacan'. ${ }^{18}$ Ultimately, aligned with literary writers, such philosophers and human scientists 'have one great advantage over the ideologists in that they frequently change scenarios, they get tired of the old ones and invent new ones, equally convincing. ${ }^{19}$

The closing sections of 'Id Is, Is Id?' detail the opposite - a more 'ideological' tendency, to use Brooke-Rose's terminology - through the example of Harold Bloom. ${ }^{20}$ For Brooke-Rose, Bloom exemplifies those of Freud's 'disciples' prone to 'a certain literalness, and the creation of a new theology', so becoming a cautionary tale of criticism's tendency to 'fall into the traps of language and notably of the copula and its protean forms, behind which is desire and dogma and mastery'. ${ }^{21}$ In all, 'Id Is, Is Id?' co-opts the insights of deconstruction as a way of justifying Brooke-Rose's critical eclecticism, a paradoxical manoeuvre that conforms in a deeper sense with a deconstructive analytic: in providing the terms for Brooke-Rose's approach to criticism, deconstruction also clears the grounds for its own abandonment. What remains is a critique of mastery that operates at both the level of critical content and form, achieved in part through an affirmation of literary discourse as a kind of thinking. Therefore, as I will go on to suggest, in Remake, the novelistic mode, and the figure of Bletchley Park prove ultimately for Brooke-Rose to be the better forum for her critique of mastery.

\section{$* * *$}

In de Man's work, the theme of mastery carries through from Allegories of Reading to the influential article of 1982, 'The Resistance to Theory'. As the title of this article implies, de Man's main purpose is to detail the aspects of Theory that are 'so threatening' as to provoke 'such strong resistances and attacks'. His discussion of this topic includes the routine answer given in university literature departments of this period that Theory 'upsets rooted ideologies by revealing the mechanics of their workings' as well as destabilizing 'the established canon of literary works' and blurring 'the borderlines between literary and non-literary discourse'. ${ }^{22}$ But such claims prove unsatisfactory for de Man, while also providing an opening for his article to take a more typically deconstructive turn. One of de Man's primary figures in the article is the classical trivium, 'which considers the sciences of language as consisting of grammar, rhetoric and logic'. ${ }^{23}$ Though 'literariness, the use of language that foregrounds the rhetorical over the grammatical and the logical function' might destabilize the more formal and systematic dimensions of the trivium, de Man's analysis ultimately values these latter dimensions for the way in which their very operation reveals their impossibility: 'the grammatical decoding of a text', for example, 'leaves a residue of indetermination that has to be, but cannot be, resolved by grammatical means, however

\footnotetext{
${ }^{17}$ Brooke-Rose, Stories, Theories and Things, p. 31. See also Jacques Derrida, 'The Supplement of Copula: Philosophy Before Linguistics', in Margins of Philosophy, trans. by Alan Bass (Chicago: University of Chicago Press, 1982), pp. 175-202.

${ }_{18}$ Brooke-Rose, Stories, Theories and Things, p. 33.

${ }^{19}$ Brooke-Rose, Stories, Theories and Things, p. 37.

${ }^{20}$ Notably, Bloom was associated at this time with de Man through the 'Yale School' of deconstruction, one of the looser institutional fictions of that period.

${ }^{21}$ Brooke-Rose, Stories, Theories and Things, pp. 37, 44.

22 Paul De Man, 'The Resistance to Theory', Yale French Studies, 63 (1982), 3-20 (pp. 11-12).

${ }^{23}$ De Man, 'The Resistance to Theory', p. 13.
} 
extensively conceived'. ${ }^{24}$ De Man's concluding gesture, then, is to emphasize the inevitability of this 'residue of indetermination', an irreducible excess or supplement that attends to any theoretical effort:

Nothing can overcome the resistance to theory since theory is itself this resistance. The loftier the aims and the better the methods of literary theory, the less possible it becomes. [...] the more it is resisted, the more it flourishes, since the language it speaks is the language of self-resistance.

Elsewhere in the concluding passages of the article, de Man states that a perfect rhetorical (rather than grammatical or logical) reading of a text would itself end up being 'totalizing (and potentially totalitarian) ${ }^{25}$. And so, the resistance to theory is symptomatic of the faults built into theory itself, its permanent incompleteness, its incapacity to master either itself or its ostensible objects. This problematic, de Man argues, represents a positive value that theory can productively attest to as a form of resistance in itself.

There is an uncanny quality to summarizing de Man's 'The Resistance to Theory', four decades after its publication. Whereas Brooke-Rose's writing from the same period retains its professed eccentricity, its pleasingly personal set of coordinates, de Man's article today seems indistinct both for its familiarity and its anachronism. The institutional prominence of deconstruction in Anglophone literary criticism of the 1980s and early 1990s seems now to be one of many documents from the twentieth-century archive of the discipline of literary studies. Indeed, this is so much the case that at the beginning of the third decade of the twenty-first century, we even exist at a remove from deconstruction's resulting reduction to method and orthodoxy for the purposes of summary, pedagogy, and critique. Put another way, today, deconstruction's force is perhaps only recoverable as history. While we might explore queer theory or postcolonial criticism of the 1980s as part of the genealogy of current work in those fields, today deconstruction of the sort practised by de Man might even fail to make the reading list, the lecture list, or the reference list. For my present purposes, therefore, de Man's ideas are worth reciting in part as a way of hearing some of the echoes of the intellectual ambience from which Brooke-Rose's fiction and criticism of the 1980s-90s emerged. More importantly, 'The Resistance to Theory' also helpfully draws attention to one aspect of deconstruction as a literarycritical practice that has a direct bearing on Remake, and its return to Bletchley Park. Reading de Man and Brooke-Rose side-by-side, we see a distinct challenge to the model of criticism and knowledge-creation as a will-to-mastery, and a positive valuation of critical methods that can comprehend irreducibility, deferral, indeterminacy, and incompleteness. As I will go onto discuss, in view of both the de Man affair and Brooke-Rose's Remake, the question that follows relates to what exactly fills the gap once mastery is discarded.

The facts of the de Man affair are well-known, especially since they were revisited in Evelyn Barish's inflammatory biography of $2014 .{ }^{26}$ Four years after de Man's death in late 1983, a Belgian scholar, Ortwin de Graef discovered a range of journalistic writings published by de Man before and during the German occupation of Belgium of May 1940-September 1944. ${ }^{27}$ Following the public revelation of this information, focus fell in particular on the fact that from December 1940, de Man started writing a cultural column for Le Soir - one of Beligum's main newspapers, and at that point in time under German control. De Man wrote 170 articles over two years for Le Soir, many of which, as Shoshana Felman puts it, were characterized by a

\footnotetext{
${ }^{24}$ De Man, 'The Resistance to Theory', pp. 14, 15.

${ }^{25}$ De Man, 'The Resistance to Theory', p. 20.

${ }^{26}$ See Evelyn Barish, The Double Life of Paul de Man (New York and London: Liveright, 2014).

27 These writings, including work for collaborationist publications and otherwise, were collected together in Paul de Man, Wartime Journalism, 1939-43, ed. by Werner Hamacher, Neil Hertz, and Thomas Keenan (Lincoln, NE: University of Nebraska Press, 1988).
} 
'general motif of admiration for German literature and culture and the occasional propounding of a cultural renaissance in light of this identification with the Germanic model culture'. Most damningly, however, to quote Felman again, one article 'stands out as truly compromising' - an explicitly anti-Semitic piece titled 'Les Juifs dans la literature actuelle' ('The Jews in Present-Day Literature'), published 4 March 1941 'in a special afternoon edition of Le Soir devoted to antiSemitic propaganda'. ${ }^{28}$ De Man emigrated to the US in 1948, so beginning the progression of his academic career there; his activities in occupied Belgium remained a secret. Among the details that emerged in the late 1980s was the fact that information about his wartime writings had been disclosed anonymously to his employer when he was working at Harvard. A draft of a response letter was also discovered, written by de Man to the comparatist and theorist of the avant-garde Renato Poggioli - then Director of the Harvard Society of Fellows - in which de Man admitted writing for Le Soir, while also stating that 'like most of the other contributors', he 'stopped doing so when nazi thought-control did no longer allow freedom of statement'. ${ }^{29}$

The responses to and impact of the revelations about de Man's past are as equally wellknown as the facts of those revelations. The de Man affair was perhaps the paradigmatic incident of the Theory Wars: in retrospect, it appears to be the gravitational centre around which comparable incidents spin, for example the controversy in the University of Cambridge around Colin MacCabe's appointment and later around Jacques Derrida's honorary degree, or the Sokal incident, or the attack on Judith Butler's work in Philosophy and Literature's 'Bad Writing Contest'. ${ }^{30}$ In a North American context, the de Man affair became a representative instance of the way in which debates about the aims and methods of humanities scholarship were mobilized in another set of semi-confected 'wars', related to questions of culture. Discussion of the revelations about de Man was extensive, both in academic forums and in the wider public sphere. Rather than survey them at length here, I want to stress two characteristic features of the discussion around de Man that are pertinent to my discussion of Brooke-Rose.

Firstly, for my purposes, it is important to note the fact that the de Man affair, with its moment of revelation, and its central set of crimes, becomes a locus of suspicion. In the Spring 1988 issue of Critical Inquiry, Jacques Derrida published a long article titled 'Like the Sound of the Sea Deep within a Shell: Paul de Man's War' - a subtle defence of de Man. Suspicion becomes one of the key orienting points in this article, and is presented as an approach to de Man that should be resisted. '[F]or almost twenty years, I had never had the least reason to suspect my friend could be the author of such articles', Derrida states, while also quoting at the end of the article a newly-revealed testimony from a friend of de Man's from 'those dark years', who also 'confirm[s] that never, neither before nor after the war, did Paul de Man's remarks or attitudes permit one to suspect an antisemitic opinion - which, let me say in passing, would have ended our relations'. ${ }^{31}$ Derrida also presents de Man as wanting to resist suspicion in his letter to Poggioli: 'he wished in 1955 never to have done anything that could be suspected of Nazism or collaboration. ${ }^{32}$ In all of these instances, the fact of de Man's wartime writings is not under dispute. Derrida's main task, then, is to resist suspicion becoming the main hermeneutic attached to those writings. The reason is clear: in Derrida's reckoning, suspicion is contagious, and diffuses beyond the initial object to which it is attached. The 'policeman's petty game' offers 'a whole cartography of false leads, beginning with what de Man wrote and gave us to think on

\footnotetext{
${ }^{28}$ Shoshana Felman, 'Paul de Man's Silence', Critical Inquiry, 15 (1989), 704-44 (pp. 711-12).

${ }^{29}$ Quoted in Jacques Derrida, 'Like the Sound of the Sea Deep within a Shell: Paul de Man's War', trans. by Peggy Kamuf, Critical Inquiry, 14 (1988), 590-652 (p. 636).

${ }^{30}$ On MacCabe in Cambridge, see Francis Mulhern, 'The Cambridge Affair', Marxism Today, March 1981, pp. 27-8; on Derrida in Cambridge, see Niall Gildea, Jacques Derrida's Cambridge Affair: Deconstruction, Philosophy and Institutionality (London: Rowman \& Littlefield, 2020); on the Sokal incident see John Guillory, 'The Sokal Affair and the History of Criticism', Critical Inquiry, 28 (2002), 470-508; on Butler and the Bad Writing Contest, see Cathy Birkenstein, 'We Got the Wrong Gal: Rethinking the "Bad” Academic Writing of Judith Butler', College English, 72 (2010), 269-83.

${ }^{31}$ Jacques Derrida, 'Like the Sound of the Sea ', pp. 600, 651.

32 Derrida, 'Like the Sound of the Sea', p. 637.
} 
the theme of memory, mourning, and autobiography. ${ }^{33}$ Derrida recognizes quickly that de Man's entire critical method, concerned with textual effacement on the one hand, and the irreducibility of knowledge on the other could be engulfed by a suspicious reading that sees nothing but a prolonged intellectual excuse for earlier personal (and writerly) crimes:

Can one, ought one to take the reading possibilities that de Man himself offers us and manipulate them as arms, as a suspicion or an accusation against him in a "décision de justice," as we say in French, in a final judgment, authorizing oneself this time to decide in the absence of proof or knowledge? ${ }^{34}$

In his article on de Man, Derrida sees that deconstruction tout court is at stake, and through the revelations about de Man is at risk of being charged with complicity. As Derrida resists the suspicious analytic that would generate such a charge, he cannot help but reinscribe its centrality to the debate about de Man.

Secondly, I want to note the importance in the debate about de Man's wartime writings of forms of knowledge that constitute what in Brooke-Rose's terminology would be called mastery, or in de Man's would equate to something 'totalizing (and potentially totalitarian)'. In one of the most prominent and incendiary texts of the 'culture wars', Roger Kimball's Tenured Radicals, 'The Case of Paul de Man' is given its own chapter, based on an earlier article for the New Criterion. For Kimball, the charge of 'nihilism' levelled against deconstruction 'has now acquired existential support of the most damaging kind': 'it is a rum thing when the patron saint of a literary movement that has so arrogantly proclaimed itself a champion of freedom is brutally exposed as having trafficked with a political force whose very essence was the denial of freedom'. Going on to discuss Geoffrey Hartman's writing on the de Man affair, Kimball sees the 'deconstructionist habit of intellectualizing reality' resulting in 'a deviousness that willingly forsakes the most basic moral distinctions in its pursuit of ever more clever rhetorical constructs'. ${ }^{35}$ Here, the passage from suspicion to what Derrida calls 'décision de justice' is clear - the evidence has been discovered, and the judgement assured.

The fact that Kimball's Tenured Radicals was a prominent lightning-rod in the US 'culture wars', is reflected in the fact that it is discussed so incisively by Eve Kosofsky Sedgwick at the start of an article of 1991, 'Jane Austen and the Masturbating Girl'. Sedgwick notes that the title of her article in its original iteration as a paper at the MLA conference becomes in Kimball's book 'the Q.E.D. of phobic narratives about the degeneracy of academic discourse in the humanities'. Kimball, Sedgwick notes, cites the title

quite as if he were Perry Mason, the six words a smoking gun: the warm gun that, for the journalists who have adopted the phrase as an index of depravity in academe, is happiness-offering the squibby pop (fulmination? prurience? funniness?) that lets absolutely anyone, in the righteously exciting vicinity of the masturbating girl, feel a very pundit. $^{36}$

Albeit conveyed in a different register and with a different set of stakes, Sedgwick's concerns are close to Derrida's, with his attention to the limitations of the 'policeman's petty game'. But in Sedgwick's career, such considerations represented the beginning of a trajectory that, by the end

\footnotetext{
${ }^{33}$ Derrida, 'Like the Sound of the Sea', p. 642.

${ }^{34}$ Derrida, 'Like the Sound of the Sea', p. 643.

35 Roger Kimball, Tenured Radicals: How Politics Has Corrupted Our Higher Education (New York: Harper \& Row, 1990), pp. 102-3, 113. See also Roger Kimball, 'Professor Hartman Reconstructs Paul de Man', New Criterion, 6.8 (1988), 36-43; and Geoffrey H. Hartman, 'Blindness and Insight', New Republic, 7 March 1988, pp. 26-31.

${ }^{36}$ Eve Kosofsky Sedgwick, 'Jane Austen and the Masturbating Girl', Critical Inquiry, 17 (1991), 818-37 (pp. 818-19).
} 
of the decade, had resulted in the earliest and most significant volley in what has now come to be called, in Rita Felski's phrase, the 'method wars'. ${ }^{37}$

Sedgwick's influential essay of 1997 on paranoid and reparative reading proceeds from the insight that in 'recent U.S. critical theory [...] to apply a "hermeneutic of suspicion" is, I believe, widely understood as a mandatory injunction rather than a possibility among other possibilities. ${ }^{38}$ This essay is now so well-known that I will only detail its argument briefly: that is, drawing on the work of Melanie Klein and Silvan Tomkins, Sedgwick offers a thoroughgoing diagnosis of the preoccupations and limits of the paranoid critical disposition, before working through the potentials of an alternative, reparative approach. In my present discussion, the key point to take from this sketch of Sedgwick's intellectual trajectory is as follows: reading this essay alongside 'Jane Austen and the Masturbating Girl', Sedgwick reveals that, at root, Kimball and other 'culture warriors' share a set of critical predilections with precisely those critics they sought so vehemently to oppose - to the detriment of both sides. The culture and theory 'wars' of the late 1980s/early 1990s make up the intellectual and cultural forces that led Sedgwick to diagnose and then to put pressure on suspicion and mastery as ways of knowing, so generating the demand for alternatives. As I turn back to Brooke-Rose, my suggestion is that Sedgwick was not alone, and that in reading Remake as another expression of the context I have detailed here, we might understand the impetus behind Brooke-Rose's return to Bletchley Park.

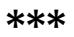

Bletchley Park is, says Remake, 'Tess's first training of the mind, a first university'. This statement follows a sequence in which the particular entailments of such a claim are narrativized in a normative sense. Embarking on her work reading teleprints of intercepted messages, Tess 'becomes familiar with individual units, types of reports and order, but can't grasp the whole, can't bear not to grasp the whole', and so, working 'overtime', produces, an 'enormous chart on a roll of white paper' that maps the German chain of command. Gaining the notice and approval of her colleagues, 'Tess bathes in admiration, starts enjoying the work and understanding things. Mastering things. ${ }^{39}$ Brooke-Rose suggests here that the passage from piecemeal familiarity, through a desire to grasp the whole, to a socially-sanctioned model of labour and understanding, leads to mastery. Noted without additional comment, we are led to assume that such a passage is uncontroversial.

Brooke-Rose's depiction of Bletchley Park in Remake centres on issues of knowledge. But it is only in the sequence quoted here that mastery is invoked as a horizon to that knowledge, and an achievable one at that. Conversely, Tess's informal induction at Bletchley Park is more indicative of the partial, fallible, improvised status that knowledge actually has in the world depicted in Remake. 'All German signals are intercepted, well, not all, not those sent by landline in Germany and France, but all those sent over the air in operational areas,' Tess is told, when being introduced to the interception of enemy messages. Of the Enigma machine, she is told that 'cryptographers break quite a lot every day, especially the general Luftwaffe key, called Red here. Well, not every day, and not every key, and not always on the day, but more and more often' ${ }^{40}$ The progression from information to understanding falters in these instances - it is not even explainable in the way that Tess's attempt to understand the German chain of command seems to be. From its first depictions of Bletchley Park, therefore, Remake shifts its emphasis onto the process of interpretation, and that process's constitutive incompleteness.

\footnotetext{
${ }^{37}$ Rita Felski, 'Introduction', New Literary History, 45.2 (2014), v-xi (p. v).

${ }^{38}$ Eve Kosofsky Sedgwick, 'Paranoid and Reparative Reading; or You're So Paranoid, You Probably Think This Introduction Is about You' in Novel Gazing: Queer Readings in Fiction, ed. Sedgwick (Durham, NC and London: Duke University Press, 1997), pp. 1-37 (p. 5).

${ }^{39}$ Brooke-Rose, Remake, pp. 106-7.

${ }^{40}$ Brooke-Rose, Remake, p. 103.
} 
As an act of memory-work and life-writing, Brooke-Rose's depiction of Bletchley Park resonates strongly with its context of articulation. The preoccupations of academic literary criticism of the 1980s-90s become the lens through which Brooke-Rose reads her own past in the 1940s. Moreover, these two historical moments are twinned as a means of diagnosing a deeper set of cultural concerns, especially regarding the hermeneutics of suspicion. Like Rita Felski's field-defining The Limits of Critique, from 2015, Remake reveals suspicion to be 'a broader cultural sensibility composed out of the steady drip-drip of bureaucratic acts, a loose constellation of practices and postures that is diffused through society via the legal and executive branches of the modern state. ${ }^{41}$ This is particularly clear as Brooke-Rose shows suspicion to enter in where other hermeneutics fail. Tess learns to reject official newspaper or wireless information: 'out of fear of being unable to distinguish inside from outside information' she 'stops reading the papers altogether, so as to be sure everything known is secret'. But this easy distinction between 'inside' and 'outside' accounts, and the veracity of 'secret' information quickly breaks down, with 'talk', 'back-research', and 'chatting' leading her to learn of 'many bunglings higher up, and much dissension between Whitehall departments'. ${ }^{42}$ 'Inside' information is just as unbelievable as 'outside', and 'secret' knowledge has its own secrets, variously, informally, and unofficially uncovered, if at all. A suspicious attitude becomes in Bletchley Park both the means and end to knowledge, a disposition that suffuses the Tess's activities and her response to her surroundings.

As a consequence, Remake puts particular pressure on the epistemology of suspicion, and any claim it might have to authority. Settled into her work at Bletchley Park, Tess is invited for coffee by Jonathan a 'lecturer in Mediaeval German at London University'. The two soon find time for 'spend[ing] hours bicycling along the carless roads and sitting in solitary fields under summer trees with Tristan, Siegfried, Parzifal and the Minnesang'. Following Jonathan's 'increasing intensity and number of little notes with jocular glosses on Middle High German', Tess 'doesn't decode anything' and so 'innocently writes an imitation letter to Jonathan at home on leave'. The relationship ends, as 'Jonathan is furious. Jonathan has a wife', though Tess 'knew this, and can't understand why such a stimulating pastime on war duty has to be kept secret'. ${ }^{43}$ Later in the novel, Tess, 'not jealous or suspicious by nature' encounters similar treatment from her husband Janek, who believes that 'any other relationship' outside their union is 'a transfuge'. Removing 'portraits of Janek's parents from the wall for framing in old gold as a birthday present, Janek notices at once, accusing Tess as jealous iconoclast'. ${ }^{44}$

In both of these instances, Bletchley Park's particular orientation of decoding, secrecy, and suspicion are shown to carry over to the domain of personal relationships. Tess refuses to subscribe to the anticipative temporality of suspicion, where actions must be foreclosed in advance by the suspicions they could arouse. This is what Sedgwick calls the 'unidirectionally future-oriented vigilance' of paranoid critical approaches, a 'complex relation to temporality' in which, 'because there must be no bad surprises, and because to learn of the possibility of a bad surprise would itself constitute a bad surprise', then 'bad news' must 'be always already known'. ${ }^{45}$ In exposing just such a suspicious epistemology, and its temporal effects, Brooke-Rose also reveals the way structures of gendered power are enforced along suspicious lines: codes of secrecy and suspicion arbitrate women's behaviour, and Tess suffers for transgressing these codes. An alternative form of 'intelligence work' is sketched out here - one equally bound up with secrecy, suspicion, power, and violence as the traditional definition of the term. BrookeRose depicts her/Tess's experience of personal relationships as freighted with the expectation to know how to behave, to keep up, to understand what is going on; in actively failing to do so, a

\footnotetext{
${ }^{41}$ Rita Felski, The Limits of Critique (Chicago: University of Chicago Press, 2015), p. 47.

42 Brooke-Rose, Remake, p. 108.

${ }^{43}$ Brooke-Rose, Remake, pp. 110-11.

44 Brooke-Rose, Remake, pp. 158-9.

${ }^{45}$ Sedgwick, 'Paranoid and Reparative Reading', p. 10.
} 
more creative, if difficult, space is cleared for different orientations towards the world, and to what can be known of that world.

As with her depiction of the institutional workings of Bletchley Park, Brooke-Rose's response to the epistemology of intelligence work in its standard sense is also ultimately characterized at a verbal level by constant slippage, by the immediate reversal or qualification of categorial statements:

Tess acquires a reverence for knowledge, tinged with the absolute secrecy and pleasurable guilt (Is intercepting Fair Play? Apparently the question was asked during the First War), but also glee, soon transformed into an awareness of the power knowledge gives. ${ }^{46}$

This passage is key to understanding the use Bletchley Park has for Brooke-Rose, placing its depiction in Remake within her broader body of work - both literary and critical. In an earlier version of the passage, from an interview of 1993, Brooke-Rose concludes by stating that 'knowledge has been a constant theme, in one way and another, throughout my work'. ${ }^{47}$ As a statement about knowledge, then, this passage exists at a remove from Tess's movement from familiarity through understanding to mastery that characterizes her initial working life at Bletchley Park. Here, knowledge is not codified but revered, the lexicon of suspicion (secrecy, guilt) is counterbalanced with pleasure, and questions of power also announce themselves. As with Tess's resistance to the entry of suspicious hermeneutics into her personal relations, here Brooke-Rose posits a model of knowledge that, to repeat de Man's terms, is characterized by a 'residue of indetermination' and a 'language of self-resistance'. In common too with BrookeRose's critical work of the same period, Remake shows us that the gaps that necessarily open up in this model of knowledge can be filled non-suspiciously, non-transactionally, and without finality.

Among its many permutations and uses in Remake, intelligence work provides a kind of mastertrope for Brooke-Rose as autobiographical subject too:

Reading the whole war, for example, every day, from the enemy viewpoint, the British being the enemy, like the hysterical sympathy with the enemy felt by soldiers suffering in the trenches. The writer does that, learning to imagine the other. All human beings should, in fact, but don't always. On the other hand, experiencing that same war as pure information on teleprint, index-cards and maps, well-protected in the peaceful Buckinghamshire countryside, helps to turn Tess into a detached intellectual, never experiencing the grime, the cold, the heat, the suffering, the corpses, the landmines, the tanks, except anodyned in newsreels. ${ }^{48}$

Another reason that Remake centres on Bletchley Park is for its formative impact on BrookeRose's two writerly selves: the novelist concerned with imagining alterity, and the critic concerned with the detached synthesis of information. At a broader scale, Brooke-Rose's

\footnotetext{
${ }^{46}$ Brooke-Rose, Remake, p. 107.

47 'Christine Brooke-Rose Interviewed by David Seed', Textual Practice, 7 (1993), 247- 57 (p. 248). In this interview, the early version of the passage quoted above reads: '[Bletchley Park] aroused in me, with perhaps greater intensity than I might have felt if I had gone straight into higher education, an almost mystical attitude to knowledge, tied up with absolute secrecy and perhaps guilt (was this 'fair play'?) and glee, rapidly transformed into an awareness of the power of knowledge (this one partly won the war).'

${ }^{48}$ Brooke-Rose, Remake, p. 108.
} 
comments here demonstrate the way Remake works to situate her writing on a particular set of historical, institutional, intellectual, and affective continua.

As I have shown, the two identities of fiction writer and critic overlap in important ways for Brooke-Rose, and share a concern with the valuation of certain kinds of knowledge. By the time of Remake's publication, this overlap had taken a more direct turn as Brooke-Rose began to use her critical writings to reflect on her fictional aesthetics. 'Have you ever tried to do something very difficult as well as you can, over a long period, and found that nobody notices?' Brooke-Rose says in the opening sentence of Invisible Author. 'That's what I've been doing for over thirty years. ${ }^{49}$ In her final collection of critical essays, this particular negative affect gives Brooke-Rose a framework within which she can name her critical and popular marginalization, while simultaneously, through the work of criticism, imagining the conditions of possibility that would enable her to overcome that status. 'It's true that experimenters often get ignored or forgotten for the mainstream', Brooke-Rose says in the interview with Lorna Sage included in Invisible Author, 'I'm a duck-billed platypus, and hope my beak will somehow develop in new birds'. ${ }^{50}$ As in the book's opening sentence, different instances and figurations of being ignored appear frequently in Invisible Author. But the most irksome figure of ignorance presented by Brooke-Rose less concerns matters of production than reception. As noted above, the startingpoint for Brooke-Rose's practice as an experimental novelist across her career was her use of lipograms, or constraints. However, her reception failed to register the centrality of this practice of constraint: "[i]f mentioned (e.g., in the blurb, or an interview), the fact might be repeated as mere fact or ignored. Either way, it aroused not a glimmer of curiosity. ${ }^{51}$ Reflecting on readers' responses to the absence of the verb to be in Between, Brooke-Rose notes that 'nobody, of course, noticed' until she 'mentioned it in an interview much later, whereupon it got (very) occasionally repeated without further discussion or exploration, and the one person I told sooner attributed it to the wrong novels'; she recognizes the irony too - 'you feel the loss of that kind of identity when nobody notices you'. ${ }^{52}$

Invisible Author is a compendium of affects derived from a career as a writer spent in relative obscurity. To this Brooke-Rose adjoins a reparative critical attempt to account for the causes and redress the effects of this obscurity. These two aspects of Invisible Author have in common a set of concerns about narrative experiment and formal difficulty. In the opening passage of the book, Brooke-Rose sets out one lineage for such concerns: 'the notion of difficulty, once so dear to the Moderns, is itself highly variable, but in addition it has now become unfashionable. ${ }^{53}$ Contemporary scholarship has caught up with Brooke-Rose's hint: as exemplified by Julia Jordan's recent work, Brooke-Rose is today read as one of a number of late modernist writers active in Britain in the 1960s. ${ }^{54}$ But what of the moment at the very start of the twenty-first century that Brooke-Rose speaks of in Invisible Author, which sees modernism's concerns as so 'unfashionable'? My suggestion to conclude is that in its attempts to take soundings from it two historical scenes of articulation - the 1940s of intelligence work and Bletchley Park, and the 1990s of the Theory Wars - Remake is particularly effective at valuing 'unfashionable' literary experiment and difficulty as what Sedgwick terms a reparative practice, one of, to quote Sedgwick again, 'many ways in which selves and communities succeed in extracting sustenance from the objects of a culture - even of a culture whose avowed desire has often been not to sustain them, ${ }^{55}$

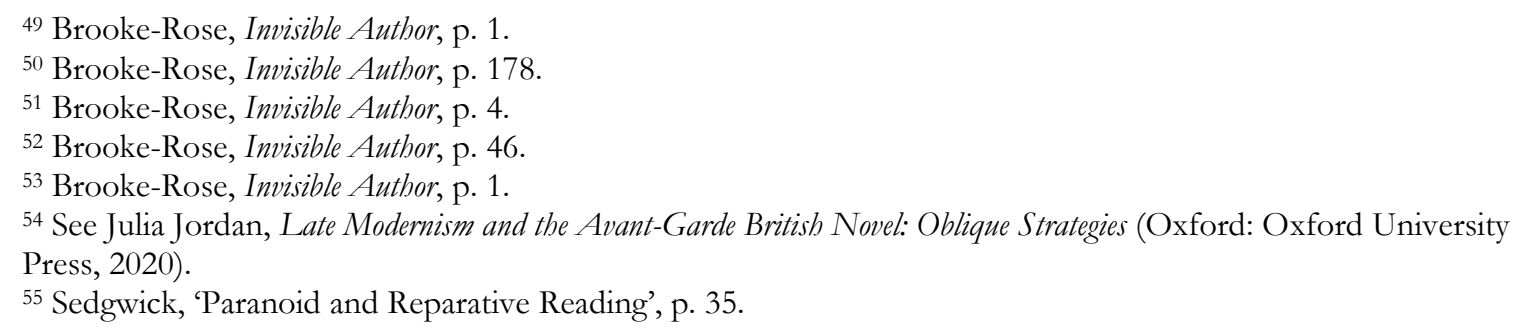


A minor mainstay of discussions and debates about French Theory in the 1980s-90s was the argument that it represented a kind of continuity modernism, taking refuge in the institution of the Anglophone university. This view was held across the political spectrum. On the left, Terry Eagleton's famous Literary Theory: An Introduction (1983) calls 'some of the later works of Barthes and Derrida [...] modernist literary texts in themselves, experimental, enigmatic and richly ambiguous', while in 1996, Fredric Jameson portrayed the legacy of the French journal Tel Quel as having failed on precisely those terms: 'instead of ending up producing a revitalised and genuinely political Modernist art, it produced that very different new thing we now call Theory. ${ }^{56}$ Meanwhile, in the conclusion to John Carey's reactionary diatribe against modernism, The Intellectuals and the Masses (1992), 'Theory' (always in scare quotes), produced by those 'eager to identify themselves as the intellectual avant-garde', is fundamentally 'in accord with early twentieth-century treatises such as Clive Bell's Art and Ortega y Gasset's The Dehumanization of $A r t .{ }^{57}$ In viewing these valuations of modernism as the emergent stakes of the latter stages of Brooke-Rose's career-long commitment to formal experiment, then another answer to my initial question - why Bletchley Park, in the 1990s? - begins to emerge in outline.

Like the rest of Brooke-Rose's experimental work, Remake operates according to a constraint too. Following a 'dreadful' draft, in which Brooke-Rose 'wrote down my life as I remembered it, in a conventional order', she brought the text into line with her usual novelistic process as she found the 'constraint I needed': 'an autobiography without personal pronouns' ${ }^{58}$ This omission can lessen the impact of some of the developmental narratives contained within Remake: Bildung, whether conveyed in the novel or in life-writing, is articulated through the personal pronoun. One such faint thread of development in Remake relates to a shift in Tess's literary interests. Aged sixteen, Tess is 'reading at last. Bleak House, Villette, all about Brussels, and Shelley, Keats, Coleridge, Milton, done at school ${ }^{59}$ But at the level of narrative discourse Brooke-Rose lets slip that such literary models have been updated: prior to her arrival at Bletchley Park, with Tess in Liverpool the narrator cites Henry James's The Ambassadors, noting that 'Strether came here off the boat and met Miss Gostrey', though 'Tess didn't know about Strether then'. ${ }^{60}$ By the time Tess is heading to Bletchley Park, 'Absalom! Absalom! and Finnegans Wake' are 'on the recently out display', Tess 'discovers Hopkins, Whitman, Eliot', and then registers the moment when a 'novelist called Virginia Woolf commits suicide by drowning. ${ }^{61}$ Brooke-Rose tracks Tess's transition from Victorian into modern reading, pushing her reader to think through the implications of such literary allegiances for Remake itself.

From its use of a literary constraint, to its shifting play of autobiographical 'selves', Remake is built around experimental procedures that are brought into even starker relief for appearing within the often conservative and formulaic genre of autobiography. By setting up these formal commitments within a modernist lineage in a text of the end of the twentiethcentury, Brooke-Rose exhibits precisely the tendencies that David James and Urmila Seshagiri name 'metamodernist', wherein contemporary fiction is animated by the modernism of the earlier twentieth century as 'a historical antecedent, a cultural trope, and an archive of stylistic and technical possibilities'. ${ }^{62}$ But by considering Remake against the intellectual background of the

\footnotetext{
56 Terry Eagleton, Literary Theory: An Introduction (revised edn; Oxford: Blackwell, 2008), p. 121; Fredric Jameson, 'Après the Avant-Garde', London Review of Books, 12 December 1996, < https://lrb.co.uk/thepaper/v18/n24/fredric-jameson/apres-the-avant-garde> [accessed 10 June 2021]. 57 John Carey, The Intellectuals and the Masses: Pride and Prejudice Among the Literary Intelligentsia, 1880-1939 (London: Faber, 1992), p. 215.

58 Brooke-Rose, Invisible Author, p. 57.

${ }^{59}$ Brooke-Rose, Remake, p. 80.

${ }^{60}$ Brooke-Rose, Remake, pp. 82-3.

${ }^{61}$ Brooke-Rose, Remake, pp. 95-7.

${ }^{62}$ David James and Urmila Seshagiri, 'Metamodernism: Narratives of Continuity and Revolution', PML A, 129 (2014), 87-100 (p. 93).
} 
Theory Wars, we can see a deeper set of Brooke-Rose's preoccupations coalescing. As a text that exposes the limitations of forms of knowledge based in suspicion and mastery, Remake echoes an emergent tendency of its intellectual moment, finding in the scene of intelligence work and codebreaking a resonant analogy. At this level of content, Brooke-Rose's novel is not explicit about what alternatives it might privilege over suspicion and mastery - Remake's suggestions here are tentative and open-ended. At the level of form, though, Brooke-Rose is resolute. Even in an explicitly autobiographical text, Brooke-Rose's career-long commitment to formal experiment and difficulty persists. Defined by its opacity, its refusal of mastery and closure, and its openness to types knowledge not apprehended through suspicion, Remake offers a distinct kind of literary thinking into an intellectual arena searching for new horizons. 